\title{
Investigation of clinicopathological characters and gene expression features in colorectal signet-ring cell carcinoma utilizing CMS classification
}

\author{
KENSUKE TAJIRI $^{1,2}$, TOMOYA SUDO ${ }^{1,2}$, KAZUO ISHI $^{3}$, AKIHIKO KAWAHARA ${ }^{4}$, SACHIKO NAGASU $^{1,2}$, \\ SUSUMU SHIMOMURA ${ }^{1}$, KOTARO YUGE ${ }^{1}$, MITSUHIRO KATAGIRI ${ }^{1,2}$, TAKATO YOMODA ${ }^{1}$, \\ KENJI FUJIYOSHI ${ }^{1}$, KOSHI KENICHI ${ }^{1}$, TAKAFUMI OHCHI ${ }^{1}$, TAKEFUMI YOSHIDA ${ }^{1}$, \\ TOMOAKI MIZOBE ${ }^{1}$, FUMIHIKO FUJITA ${ }^{1}$, JUN AKIBA ${ }^{4}$ and YOSHITO AKAGI $^{1,2}$ \\ ${ }^{1}$ Department of Surgery, ${ }^{2}$ Research Center for Innovative Cancer Therapy, ${ }^{3}$ Biostatistics Center, ${ }^{4}$ Department \\ of Diagnostic Pathology, Kurume University Hospital, Kurume, Fukuoka 830-0011, Japan
}

Received June 3, 2020; Accepted February 4, 2021

DOI: $10.3892 / \mathrm{mco} .2021 .2260$

\begin{abstract}
Signet ring cell carcinoma (SRCC) is a rare pathological type of colorectal cancer, of which the clinicopathological features and genetic background have not yet been fully investigated. Previous research has focused on the optimization of colorectal cancer treatment utilizing consensus molecular subtyping (CMS). However, it is not known what type of CMS would be designated to SRCC treatment. In the current study, of 1,350 patients diagnosed with colorectal cancer who underwent surgery, 14 were diagnosed with SRCC. The case-control cohort that fit the clinical background of the SRCC case was constructed. Statistical comparison between the SRCC group and the case-control cohort was performed among clinicopathological variables. SRCC and well to moderately adenocarcinoma case mRNA were submitted to microarray analysis and CMS analysis. Compared with the case-control cohort, the SRCC group was located more in the right-sided colon, the lymphatic invasion was more severe and the peritoneal dissemination was more frequent. The cancer-specific survival and the progression-free survival were significantly worse in the SRCC group compared with the case-control cohort. Microarray and CMS analysis identified that one SRCC case was significantly well assigned in the CMS 4 group and the other case was assigned in the CMS 1 group. Gene set analysis revealed the upregulation of EMT
\end{abstract}

Correspondence to: Dr Tomoya Sudo, Department of Surgery, Kurume University Hospital, 67 Asahi-machi, Kurume, Fukuoka 830-0011, Japan

E-mail: sudou_tomoya@med.kurume-u.ac.jp

Abbreviations: MYC, myelocytomatosis; SRCC, signet ring cell carcinoma

Key words: colorectal cancer, signet ring cell carcinoma, consensus molecular subtyping analysis related genes and the downregulation of fatty acid, glycolysis, differentiation, MYC, HNF4A, DNA repair genes. In conclusion, the clinical characteristics of SRCC are severe but there is a possibility of the presence of different phenotypes according to CMS analysis.

\section{Introduction}

Signet ring cell carcinoma (SRCC) is a rare histological type in colorectal cancer (CRC) and it dominates only $1 \%$ of them (1). The prognosis of SRCC patients is extremely poor and it is difficult to improve it in spite of the multimodal treatment including surgery (2). Thus, to fight against this type of deadly disease, several analyses were attempted to find early clinicopathological signs and genetic features that specifically reflect the nature of SRCC in the colorectal cancer field (1-6).

The commonly speculated clinical factors of colorectal SRCC are relatively younger patients, female-dominated, advanced disease stage, right-sided, and treatment-resistant (7-14). Additionally, $\mathrm{CpG}$ island methylator phenotype- high (CIMP-high), microsatellite instability-high (MSI-high), and BRAF mutation were commonly reported as genetic features of SRCC (15-18). According to these analyses, the specific character of colorectal SRCC was gradually being unveiled. However, there still be a long way to go to establish a more efficient treatment strategy for SRCC because it is not fully characterized yet.

Consensus Molecular Subtype (CMS) analysis was proposed by Guinney et al (19). They tried to characterize colorectal cancer into 4 subtypes by utilizing gene expression profile data set being aggregated from different gene expression analysis platforms. Several clinical trials were performed and the benefit of CMS analysis was reported (20-22). The morbidity of SRCC in colorectal cancer is so rare that it is not clearly known about where this histological type of cancer is designated in CMS analysis.

The purpose of this study is to re-confirm the clinicopathological specificity of SRCC in colorectal cancer and try to elucidate the SRCC's gene expression profile and the type 
of classification in CMS analysis. Of course, there would be some limitations while utilizing the CMS analysis because the classification is not widely clinical used yet and still needs to be fine-tuned because $20 \%$ of the case does not fall within the four subtypes, however through this study, some clues of biological insight can be dug out about this extremely rare histological type of colon cancer.

\section{Materials and methods}

Study patients and diagnosis. A total of 1,350 patients who had been diagnosed with colorectal cancer and had undergone complete resection of the tumor from 1997 to 2011 in our department were enrolled in this study. Of these patients, 14 were pathologically diagnosed with SRCC, and the remaining 1,336 were diagnosed with well to moderately differentiated adenocarcinoma (well-mode DAC) (Fig. 1). Postoperative pathological staging was determined according to the seventh edition of the UICC TNM classification of malignant tumors. None of the enrolled patients underwent any chemotherapeutic treatment prior to surgery.

RNA extraction. Total RNA was extracted from frozen tumor sections (two SRCC, two differentiated AC, and five normal tissue samples) using the RNeasy Mini kit (Qiagen) according to the manufacturer's instructions, and the samples were stored at $-80^{\circ} \mathrm{C}$.

RNA amplification and labeling. cDNA was amplified from 20 ng total RNA using the Ovation ${ }^{\circledR}$ Pico WTA System V2 (NuGEN Technologies) according to the manufacturer's instructions. The amplified cDNA yield was checked using the NanoDrop 2000 spectrophotometer. Cyanine-3-labeled cDNA was prepared from $2.0 \mu \mathrm{g}$ cDNA using the SureTag Complete DNA Labeling Kit (Agilent Technologies) according to the manufacturer's instructions, and then purified and concentrated using Amicon Ultra-0.5 ml Centrifugal Filters (Merck Millipore). Dye incorporation and cDNA yield were checked using the NanoDrop 2000 spectrophotometer.

cDNA microarray analysis. The cyanine-3-labeled cDNA was mixed with $1 \mathrm{x}$ blocking agent and $1 \mathrm{X}$ hybridization buffer (50 $\mu$ l total volume), and the solution was hybridized to SurePrint G3 Human GE 8x60K Microarray v2.0 slides for $17 \mathrm{~h}$ at $65^{\circ} \mathrm{C}$ in a rotating hybridization oven. After hybridization, the microarrays were washed with GE Wash Buffer 1 for $1 \mathrm{~min}$ at room temperature followed by GE Wash Buffer 2 for $1 \mathrm{~min}$ at $37^{\circ} \mathrm{C}$ and then dried immediately by brief centrifugation. The microarrays were scanned using the High-Resolution Microarray Scanner (Agilent Technologies) to determine fluorescence intensity.

CMS classification. To perform consensus molecular subtype (CMS) classification, statistical computational software R (ver3.6.1: R Core Team (2019). R: A language and environment for statistical computing. R Foundation for Statistical Computing, Vienna, Austria. URL https://www.R-project.org/) was utilized. The data for the CMS analysis was prepared according to the report of Guinney et al (19) and the actual CMS classification was done following the instruction of R-package CMScaller (ver0.99.1) (23). Prior to the analysis, acquired cDNA microarray raw data were normalized and standardized. According to the subtypes of CMS1, CMS2, CMS3, and CMS4 classification, two of each subtype data (total 8 data) were chosen from the crc TCGA subset (colorectal TCGA gene expression data with subtype annotation) included in the CMScaller and utilized as a reference data. SurePrint G3 microarray chip used in this SRCC study mounted more than 60,000 genes thus 5,000 gene expression data that is matched with the genes utilized in CMScaller were extracted. In the SurePrint G3 chip the same genes were analyzed multiply so that those genes data were applied to the CMS analysis after calculating normalization values according to the average of each expression data by global scaling. After the data adjustment, the emat data sheet was developed and CMS caller analysis was performed.

Statistical analysis. Analyses of the clinicopathological variables and histological status of the patients were performed using JMP Pro 14.0.0 statistical software (SAS Institute, Inc.). Clinicopathological factor correlations were compared between the SRCC and case-control data set using Student's t-test and the chi-square test. Progression-free survival (PFS) and cancer-specific survival (CSS) rates were calculated using the Kaplan-Meier method and compared using the log-rank test and Wilcoxon test. Correlations between clinicopathological factors and cancer-related death were estimated using the Cox proportional hazards model. A P-value $<0.05$ was considered to indicate significance.

\section{Results}

Clinicopathological characteristics of patients and outline of treatment with SRCC patients. Patients who had been treated for colorectal cancer from 1997 to 2011 at the Department of Surgery of Kurume University Hospital were enrolled in this study. Of 1,350 total patients, 14 were pathologically diagnosed with signet ring cell carcinoma (SRCC). The background and clinicopathological summary variables of SRCC the enrolled patients are summarized in Table I. There were 12 of 14 cases were male patients and the percentage of female patients was $14.2 \%$ in SRCC. The median value of SRCC patients' age was $62.57 \pm 10.68$. There were only two cases of T1-T2 in tumor depth $(14.2 \%)$ on the contrary remaining 14 cases were all T4a or T4b. Nine cases showed N2 or more lymph node metastasis and 5 cases were N0. There were 4 out of 5 cases presented peritoneal dissemination in distant metastasis. As a result of that pathological stage was as follows: Stage I 2 cases (14.2\%), stage II 1 case (7.1\%), stage III 6 cases (42.9\%) and stage IV 4 cases (28.6\%).

The locations of the primary tumors were right-sided in $8(57.1 \%)$ cases and left-sided in 6 cases $(42.9 \%)$. All of the SRCC patients had taken a primary tumor resection and D3 lymphadenectomy. Adjuvant chemotherapy or chemotherapy plus radiotherapy was performed in 8 out of 14 cases. There were 6 out of 8 cases who underwent adjuvant therapy experienced tumor recurrence and metastasis. Lung metastasis was verified in one case and the remaining 5 cases were all peritoneal dissemination recurrence.

Background matched case-control study. A case-controlled cohort that matched with the SRCC cohort in the same 


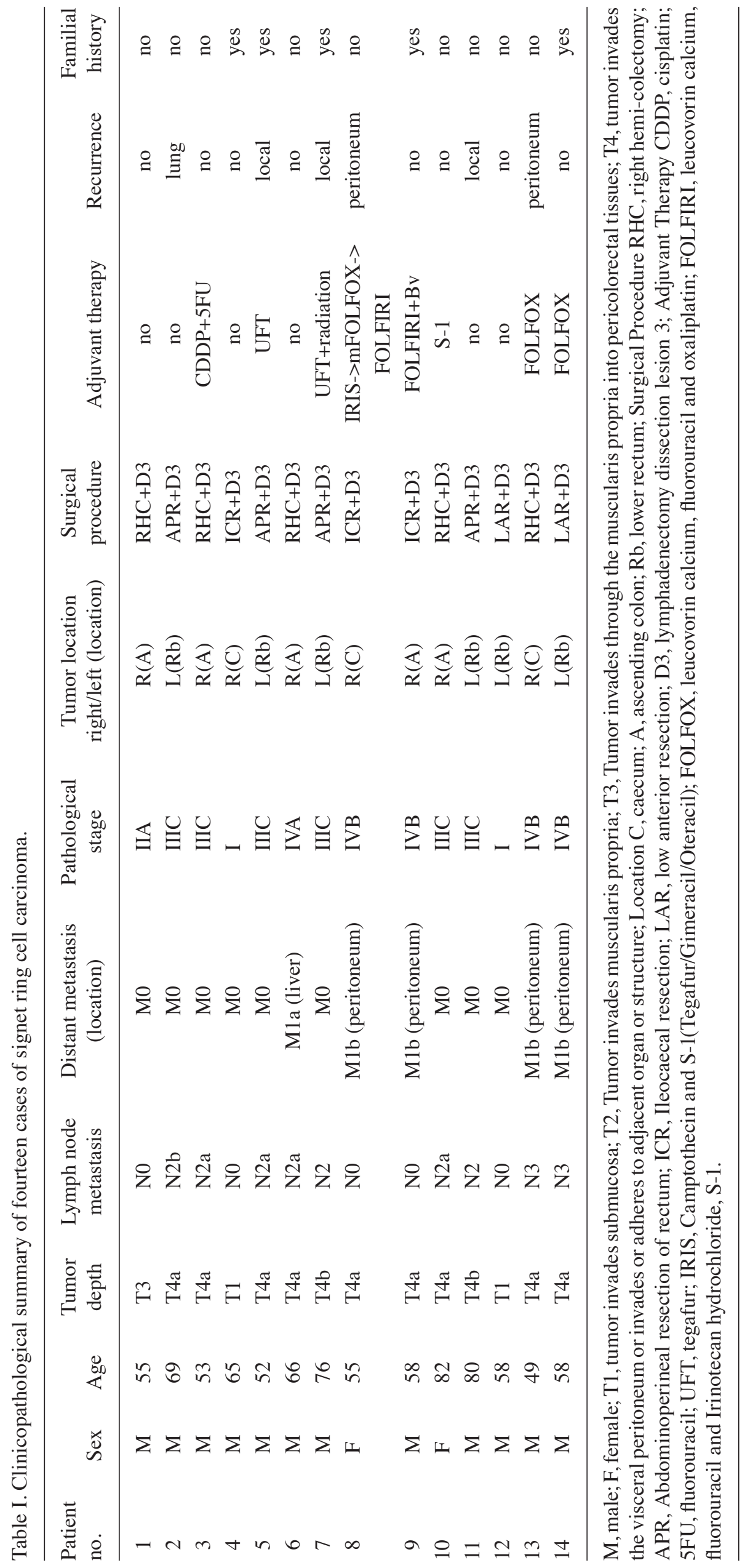



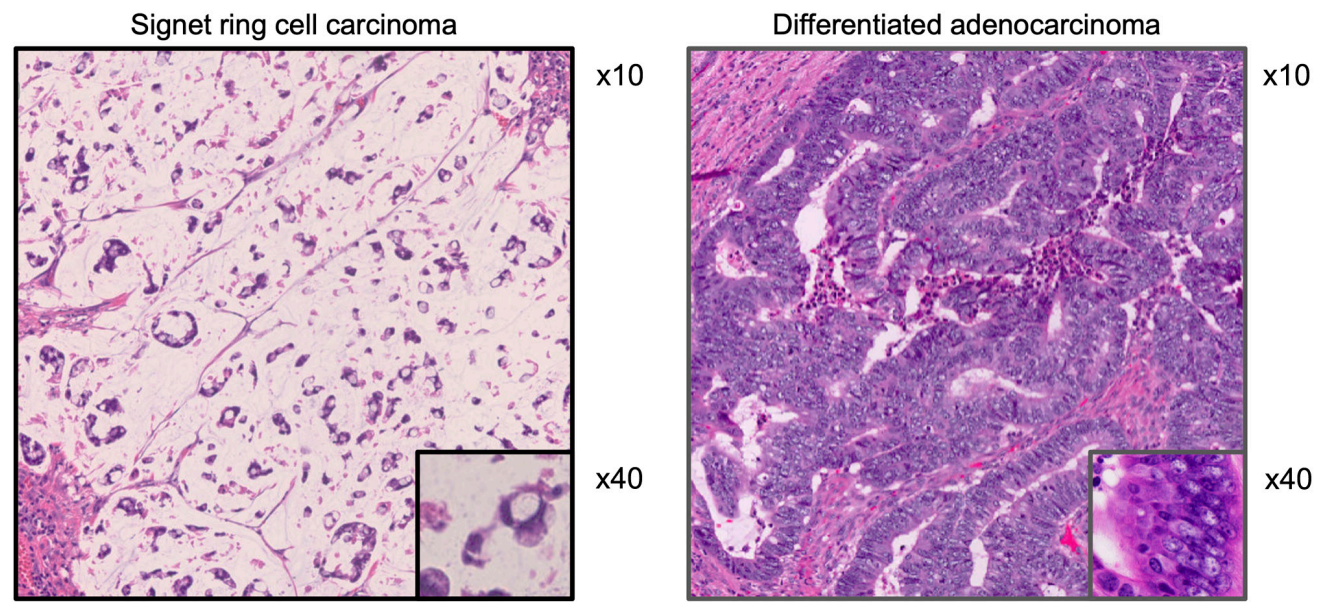

Figure 1. The representative microscopic view of signet ring cell carcinoma in colorectal cancer. Tumor tissue was stained with Hematoxylin and Eosin. The right is a low magnified view and the left is a highly magnified view.

treatment period in well and moderately differentiated adenocarcinoma cases was constructed to re-confirm the clinicopathological and prognostic features of SRCC. The cancer-specific survival (CSS) and the progression-free survival (PFS) were compared between the SRCC group and the case-control cohort group. As shown in Fig. 2 the prognosis of SRCC in CSS and in PFS was significantly worse than that of the case-control group.

Clinicopathological variables were compared between the SRCC group and the case-control group. There was no significant difference in age, gender, tumor depth, lymph node metastasis, distant metastasis, and pathological stage between the two groups (Table II). The primary location of the tumor is more frequently right-sided in the SRCC group than that in the case-control group. There was a more frequent tendency of lymphatic invasion in the SRCC group than that of in a case-control group. On the other hand, there was no significant difference in vascular invasion between the two groups. There was no significant difference between liver and lung metastasis in both groups but peritoneal dissemination more frequently occurred in the SRCC group. There was no significant difference in the status of familial history between the two groups Table II.

Microarray analysis of altered genes in SRCC. Microarray analysis was performed on mRNA samples extracted from frozen tumor tissues of SRCC and well-differentiated adenocarcinoma. Of the 58,717 differentially expressed genes extracted from the analysis, 1,445 showed significant differences between the SRCC and well-differentiated adenocarcinoma cases. The top 50 most significantly altered genes are shown in Tables III and IV.

In those tables, inflammation-related genes such as Tumor Necrosis Factor (TNF), heat shock protein (HSP), interferon-gamma (IF- $\gamma$ ), and interleukin-17 (IL-17) were shown as a commonly up-regulated genes in the SRCC group. Conversely, such as cadherin 1 (CDH1) and cadherin EGF Lag seven-pass G-type receptor (CELSR1) both genes related to epithelial cells were identified as a commonly down-regulated gene in SRCC.

CMS analysis of SRCC cases. According to the subtypes of CMS1, CMS2, CMS3, and CMS4 classification, two each data were chosen from the CRC TCGA subset (colorectal TCGA gene expression data with subtype annotation) included in the CMScaller and utilized as a reference data. SRCC microarray data were processed with the reference data.

One of the SRCC data was assigned into the CMS1 however it was not statistically significant and the other data were assigned into CMS4 with a statistically significant correlation (Fig. 3). Both two cases of well-differentiated adenocarcinoma were assigned to CMS2 (Table V).

Gene Set Analysis packaged in CMS caller was performed to investigate the comprehensively altered genes in the CMS4 assigned SRCC case, then the up-regulation of epithelial Mesenchymal transition (EMT) related genes and the down-regulation of fatty acid, glycolysis, differentiation, MYC, and DNA repair-related genes were identified as mainly changed gene expression elements in SRCC (Table VI).

\section{Discussion}

Through this study, we re-confirmed that the morbidity of SRCC in colorectal cancer is quite low and the prognosis of it was significantly worse compared with the conventional histological type as previously reported. Comparison of clinicopathological factors also verified that the primary location of the tumor was right-sided and the peritoneal dissemination was frequently observed in SRCC. Microarray and following CMS analyses revealed that there was a specific gene expression pattern in colorectal SRCC.

There were only 14 SRCC cases (1.04\%) out of 1,336 colorectal cancer cases who had been treated in our department from 1997 to 2011. There were several papers about the prevalence of SRCC in colorectal cancer (24-28) and each paper reported it around 1-2\%. Our result re-confirmed that the prevalence of SRCC in colorectal cancer is quite rare. In this study, the primary location of SRCC was significantly more than on the right side compared with the case-control cohort group. The same fact was reported by Kim et al and they stated that the tumor histologically containing SRCC element tended to be on the right side of the colon (29). So it can be mentioned that there must be a common clinicopathological nature in SRCC characterizing to be in specific locations. 
Table II. Comparison of clinicopathological characteristics of signet ring cell carcinoma group with well to moderately differentiated adenocarcinoma group in the case-control cohort.

\begin{tabular}{|c|c|c|c|}
\hline Clinicopathological variables & Signet ring cell group $(n=14)$ & $\begin{array}{l}\text { Well to moderately differentiated } \\
\text { group }(n=42)\end{array}$ & P-values \\
\hline Age mean $\pm \mathrm{SD}$ & $62.57 \pm 10.68$ & $62.57 \pm 10.42$ & 1.0 \\
\hline $\operatorname{Sex}(\%)$ & & & 0.22 \\
\hline $\mathrm{M}$ & $12(85.71)$ & $29(69.05)$ & \\
\hline $\mathrm{F}$ & $2(14.29)$ & $13(30.95)$ & \\
\hline Tumor depth (\%) & & & 0.29 \\
\hline $\mathrm{T} 1-\mathrm{T} 2$ & $2(14.29)$ & $12(28.57)$ & \\
\hline T3-T4 & $12(85.07)$ & $30(71.43)$ & 0.29 \\
\hline Lymph node metastasis (\%) & & & 0.53 \\
\hline $\mathrm{N}^{-}$ & $5(35.71)$ & $19(45.24) /$ & \\
\hline $\mathrm{N}^{+}$ & $9(64.29)$ & $23(54.76)$ & \\
\hline Distant metastasis (\%) & & & 0.39 \\
\hline $\mathbf{M}^{-}$ & $9(64.29)$ & $32(76.19)$ & \\
\hline $\mathrm{M}^{+}$ & $5(35.71)$ & $10(23.81)$ & \\
\hline TNM stage $(\%)$ & & & 0.11 \\
\hline $0-\mathrm{II}$ & $3(21.43)$ & $19(45.25)$ & \\
\hline II-IV & $11(78.57)$ & $23(54.76)$ & \\
\hline Tumor location (\%) & & & $0.0063^{\mathrm{a}}$ \\
\hline Right & $8(57.14)$ & $8(19.05)$ & \\
\hline Left & $6(42.86)$ & $34(80.95)$ & \\
\hline Lymphatic invasion (\%) & & & 0.053 \\
\hline $\mathrm{Ly}^{-}$ & $2(14.29)$ & $18(42.58)$ & \\
\hline $\mathrm{Ly}^{+}$ & $12(85.71)$ & $24(57.18)$ & \\
\hline Vascular invasion (\%) & & & 0.22 \\
\hline $\mathrm{V}^{-}$ & $2(14.29)$ & $13(30.95)$ & \\
\hline $\mathrm{V}^{+}$ & $12(85.71)$ & $29(69.05)$ & \\
\hline Liver Distant Metastasis (\%) & & & 0.29 \\
\hline- & $13(92.86)$ & $34(80.95)$ & \\
\hline+ & $1(7.14)$ & $8(19.05)$ & \\
\hline Lung Distant Metastasis (\%) & & & 0.56 \\
\hline- & $14(100)$ & $41(97.62)$ & \\
\hline+ & $0(0)$ & $1(2.38)$ & \\
\hline Peritoneum (\%) & & & $0.0358^{\mathrm{a}}$ \\
\hline- & $10(71.43)$ & $39(92.86)$ & \\
\hline+ & $4(28.53)$ & $3(7.14)$ & \\
\hline $\begin{array}{l}\text { Familial history of lynch syndrome } \\
\text { related cancer }(\%)\end{array}$ & & & 0.92 \\
\hline Yes & $6(42.86)$ & $17(41.46)$ & \\
\hline No & $8(57.16)$ & $24(58.58)$ & \\
\hline
\end{tabular}

SRCC, signet ring cell carcinoma; DAC, differentiated adenocarcinoma; M, male; F, female. ${ }^{a} \mathrm{P}<0.05$.

There was no significant difference among lymph node metastasis between the SRCC group and case-control cohort group however, the lymphatic invasion was relatively higher and peritoneal dissemination was significantly higher in the SRCC group. The invasive character of SRCC is also clearly shown in accordance with a previous report on the pathological characteristics of SRCC $(1,17,30)$.

The prognosis between the SRCC group and case-control cohort group was compared and both CSS and PFS were significantly worse in the SRCC group than the case-control cohort 
Table III. Top 50 upregulated genes in SRCC.

\begin{tabular}{|c|c|}
\hline Gene symbol & Description \\
\hline DMGDH & Dimethylglycine dehydrogenase \\
\hline CART & $\begin{array}{l}\text { Cocaine- and amphetamine-regulated } \\
\text { transcript protein }\end{array}$ \\
\hline ASB5 & $\begin{array}{l}\text { Ankyrin repeat and SOCS } \\
\text { box-containing } 5\end{array}$ \\
\hline SEPT4 & Septin 4 \\
\hline SNTG2 & Syntrophin, gamma 2 \\
\hline RYR2 & Ryanodine receptor 2 \\
\hline CACNA2D1 & $\begin{array}{l}\text { Calcium channel, voltage-dependent, } \\
\text { alpha } 2 / \text { delta subunit } 1\end{array}$ \\
\hline LRRTM1 & $\begin{array}{l}\text { Leucine rich repeat transmembrane } \\
\text { neuronal } 1\end{array}$ \\
\hline TNFSF18 & $\begin{array}{l}\text { Tumor necrosis factor (ligand) super } \\
\text { family, member } 18\end{array}$ \\
\hline CNGA3 & Cyclic nucleotide gated channel alpha 3 \\
\hline EFHD1 & EF-hand domain family, member D1 \\
\hline ARHGEF4 & $\begin{array}{l}\text { Rho guanine nucleotide exchange factor } \\
\text { (GEF) } 4\end{array}$ \\
\hline HSPB3 & Heat shock $27 \mathrm{kDa}$ protein 3 \\
\hline PEG3 & Paternally expressed 3 \\
\hline INFG & Interferon, gamma \\
\hline SMPX & Small muscle protein, $\mathrm{X}$-linked \\
\hline NPTX1 & Neuronal pentraxin I \\
\hline KCNJ8 & $\begin{array}{l}\text { Potassium inwardly-rectifying channel, } \\
\text { subfamily } \mathbf{J} \text {, member } 8\end{array}$ \\
\hline TMOD2 & Tropomodulin 2 (neuronal) \\
\hline FAM49A & $\begin{array}{l}\text { Family with sequence similarity } 49 \text {, } \\
\text { member A }\end{array}$ \\
\hline DPP6 & Dipeptidyl-peptidase 6 \\
\hline IL17B & Interleukin 17B \\
\hline PRG-3 & Proteoglycan 3 \\
\hline CDH19 & Cadherin 19, type 2 \\
\hline MPDZ & Multiple PDZ domain protein \\
\hline GPM6A & Glycoprotein M6A \\
\hline KRTAP9-4 & Keratin associated protein $9-4$ \\
\hline MN1 & $\begin{array}{l}\text { Meningioma (disrupted in balanced } \\
\text { translocation) } 1\end{array}$ \\
\hline ARHGAP6 & Rho GTPase activating protein 6 \\
\hline NPC1L1 & $\begin{array}{l}\text { NPC1 (Niemann-Pick disease, type C1, } \\
\text { gene)-like } 1\end{array}$ \\
\hline $\mathrm{BNC} 2$ & Basonuclin 2 \\
\hline ROR1 & $\begin{array}{l}\text { Receptor tyrosine kinase-like orphan } \\
\text { receptor } 1\end{array}$ \\
\hline PRDM8 & PR domain containing 8 \\
\hline PCDHB5 & Protocadherin beta 5 \\
\hline ZNF221 & Zinc finger protein 221 \\
\hline CDH9 & Cadherin 9, type 2 (T1-cadherin) \\
\hline GRID2 & Glutamate receptor, ionotropic, delta 2 \\
\hline GRIK4 & Glutamate receptor, ionotropic, kainate 4 \\
\hline SLC4A3 & $\begin{array}{l}\text { Solute carrier family } 4 \text {, anion exchanger, } \\
\text { member } 3\end{array}$ \\
\hline CD38 & CD38 molecule \\
\hline
\end{tabular}

Table III. Continued.

\begin{tabular}{|c|c|}
\hline Gene symbol & Description \\
\hline LRRC21 & Leucine rich repeat containing 21 \\
\hline KIAA1102 & LIM and calponin homology domain 1 \\
\hline SERPINB11 & $\begin{array}{l}\text { Serpin peptidase inhibitor, clade B } \\
\text { (ovalbumin), member } 11\end{array}$ \\
\hline LAMP5 & Lysosome associated membrane protein \\
\hline GPIHBP1 & $\begin{array}{l}\text { Glycosylphosphatidylinositol anchored } \\
\text { high density lipoprotein binding }\end{array}$ \\
\hline GIT1 & $\begin{array}{l}\text { G protein-coupled receptor kinase } \\
\text { interactor } 1\end{array}$ \\
\hline $\mathrm{LRCH} 2$ & $\begin{array}{l}\text { Leucine-rich repeats and calponin } \\
\text { homology }(\mathrm{CH}) \text { domain containing } 2\end{array}$ \\
\hline DNAJB5 & $\begin{array}{l}\text { DnaJ (Hsp40) homolog, subfamily B, } \\
\text { member } 5\end{array}$ \\
\hline STK33 & Serine/threonine kinase 33 \\
\hline ZNF659 & Zinc finger protein 659 \\
\hline
\end{tabular}

SRCC, signet ring cell carcinoma.

group. The reference cohort group contains relatively old cases however a whole of cases was case-controlled and stage IVB cases were assigned in both groups. Now, multimodal treatment was introduced in colorectal cancer therapeutic strategy and as shown in Table I FOLFOX or FOLFIRI were performed even in the SRCC group so that both two groups do not have any difference in clinical background. This result is implying that SRCC has chemotherapy resistance and it leads to a worse prognosis.

In the microarray analysis, the top 50 up- and down-regulated genes were selected (Tables III and IV). As shown in the tables, numerous genes that have not been reported in SRCC studies were identified. Notably, NPC1L1 and GPIHBP1 are involved in transporting cholesterol and absorbing lipoprotein respectively. NPC1L1 is an intracellular cholesterol transporter gene and the gene was reported to be connected with colitis-associated tumorigenesis (31). GP1HBP1 was reported to be associated with lipoprotein nutrient utilization in glioma (32). As shown in Table V, fatty acid and glycolysis associated genes were down-regulated in SRCC thus, up-regulation of these genes may imply that both energy transporting molecules are necessary for the survival of SRCC and would be a key biological target for the treatment of SRCC.

One of the SRCC cases was assigned into CMS4 and the other case was assigned into CMS1 (Fig. 3; Tables V and VI) in the CMS analysis. In the CMS analysis, colorectal cancer was classified into CMS1 to CMS4 (19), and, in brief, CMS1 is MSI immune type, CMS2 is canonical type, CMS3 is a metabolic type and CMS4 is mesenchymal type. In this study, SRCC case 1 was classified into CMS4 so case 1 was revealed to have a genetic background mainly related to epithelial-mesenchymal transition (EMT).

There was a report about a bio-physiological change in colorectal cancer cell lines after the cell lines acquired chemo agent resistance (33). And after that, a couple of clinical docu- 
Table IV. Top 50 downregulated genes in SRCC.

\begin{tabular}{|c|c|}
\hline Gene symbol & Description \\
\hline FAM3D & Family with sequence similarity 3 , member D \\
\hline CDCA7 & Cell division cycle associated 7 \\
\hline AREG & Amphiregulin (schwannoma-derived growth factor) \\
\hline DSG2 & Desmoglein 2 \\
\hline CEACAM5 & Carcinoembryonic antigen-related cell adhesion molecule 5 \\
\hline TPRT & Decaprenyl Diphosphate Synthase Subunit 1 \\
\hline B3GNT3 & UDP-GlcNAc:betaGal beta-1,3-N Acetylglucosaminyltransferase 3 \\
\hline PHLDA2 & Pleckstrin homology-like domain, family A, member 2 \\
\hline ESRRA & Estrogen-related receptor alpha \\
\hline GCSH & Glycine cleavage system protein H (aminomethyl carrier) \\
\hline SLC22A18 & Solute carrier family 22 (organic cation transporter), member 18 \\
\hline TFRC & Transferrin receptor $(\mathrm{p} 90, \mathrm{CD} 71)$ \\
\hline C20ORF42 & Chromosome 20 open reading frame 42 \\
\hline TPP2 & Tripeptidyl peptidase II \\
\hline FLJ20272 & Tetratricopeptide Repeat Domain 27 \\
\hline APPBP1 & Amyloid beta precursor protein binding protein 1 \\
\hline ST14 & Suppression of tumorigenicity 14 (colon carcinoma) \\
\hline SMPD3 & Sphingomyelin phosphodiesterase 3 , neutral membrane (neutral sphingomyelinase II) \\
\hline SMP3 & Phosphatidylinositol glycan Anchor biosynthesis class Z \\
\hline TM2D1 & TM2 domain containing 1 \\
\hline MRPL45 & Mitochondrial ribosomal protein L45 \\
\hline PRKDC & Protein kinase, DNA-activated, catalytic polypeptide \\
\hline $\mathrm{ABCC} 3$ & ATP-binding cassette, sub-family C (CFTR/MRP), member 3 \\
\hline FBP1 & Fructose-1,6-bisphosphatase 1 \\
\hline MGC3265 & Prenylcysteine Oxidase 1 Like \\
\hline ZNF217 & Zinc finger protein 217 \\
\hline OCIAD2 & OCIA domain containing 2 \\
\hline FLJ22662 & Phospholipase B Domain Containing 1 \\
\hline RFC3 & Replication factor $\mathrm{C}$ (activator 1 ) $3,38 \mathrm{kDa}$ \\
\hline SORL1 & Sortilin-related receptor, L(DLR class) A repeats-containing \\
\hline CDH1 & Cadherin 1, type 1, E-cadherin (epithelial) \\
\hline RARS & Arginyl-tRNA synthetase \\
\hline LEFTY1 & Left-right determination factor 1 \\
\hline EED & Embryonic ectoderm development \\
\hline SCCPDH & Saccharopine dehydrogenase (putative) \\
\hline C20ORF24 & Chromosome 20 open reading frame 24 \\
\hline TMEM45B & Transmembrane protein $45 \mathrm{~B}$ \\
\hline SDC1 & Syndecan 1 \\
\hline MTRF1 & Mitochondrial translational release factor 1 \\
\hline ATP1B1 & ATPase, $\mathrm{NA}^{+} / \mathrm{K}^{+}$transporting, beta 1 polypeptide \\
\hline EPB41L1 & Erythrocyte membrane protein band 4,1-like 1 \\
\hline TBL2 & Transducin (beta)-like 2 \\
\hline MSI2 & Musashi homolog 2 (Drosophila) \\
\hline FANK1 & Fibronectin type III and ankyrin repeat domains 1 \\
\hline LOC283537 & Not annotated \\
\hline NOC3L & Nucleolar complex associated 3 homolog ( $\mathrm{S}$, cerevisiae) \\
\hline ALDH18A1 & Aldehyde dehydrogenase 18 family, member A1 \\
\hline GLB 1 & Galactosidase, beta 1 \\
\hline CELSR1 & Cadherin, EGF LAG seven-pass G-type receptor 1(flamingo homolog, Drosophila) \\
\hline MGC17299 & Transmembrane protein 125 \\
\hline
\end{tabular}


Table V. Statistical analysis of CMS classification of signet ring cell carcinoma and well differentiated adenocarcinoma cases.

\begin{tabular}{llcccccr}
\hline Case & Prediction & d.CMS1 & d.CMS2 & d.CMS3 & d.CMS4 & P-value & FDR \\
\hline SRCC case 1 & CMS4 & 0.6885880805 & 0.7941236723 & 0.7319281894 & 0.5330759305 & $0.001^{\text {a }}$ & 0.001 \\
SRCC case 2 & NA & 0.6179980022 & 0.7074984863 & 0.6460235957 & 0.713021697 & 0.569 & 0.569 \\
Well case 1 & CMS2 & 0.7670768658 & 0.6185472389 & 0.7328083907 & 0.7341745467 & $0.001^{\text {a }}$ & 0.001 \\
Well case 2 & CMS2 & 0.7690166154 & 0.6682347108 & 0.7220604844 & 0.8455248645 & $0.001^{\text {a }}$ & 0.001 \\
\hline
\end{tabular}

SRCC, signet ring cell carcinoma; Well, well-differentiated adenocarcinoma; CMS, consensus molecular subtype; FDR, false discovery ratio; NA, not applicable. ${ }^{\mathrm{a}} \mathrm{P}<0.05$.

ments presented the association of chemoresistance and EMT related gene alteration (34-38). EMT is a gene alteration that can explain the both phenomenon of invasive and chemoresistant characteristics of SRCC so that the result is very compatible.

Another SRCC case was assigned into CMS1 but it was not statistically significant. CMS1 is an MSI immune type and it has a character of MSI-high, CIMP high, hypermutation, BRAF mutation, and worse survival after relapse. In a study of the genetic background of colorectal cancer, RAS mutations and especially BRAF mutations were found to be particularly common in SRCC $(39,40)$. Furthermore, to take into account the result of the SRCC was significantly frequent in the right side that it reminded us that the SRCC case 2 bore CMS1 specific gene alteration on it.

The element of SRCC is considered to be the one of a poor prognostic factor however, our study revealed that SRCC cases contain a mixture of MSI-high and EMT enriched cases on it. As a result, consideration of the primary therapeutic strategy could be possible utilizing CMS analysis according to this study. One limitation of this study is the lack of information regarding the MSI and CIMP statuses of the study patients. Because MSI and CIMP affect gene expression, this is critical information. However, in this study, we could not acquire both of the information from these SRCC cases. If the information was available, it would ensure a result of this study furthermore.

Considering these limitations, further analyses involving additional SRCC cases are needed utilizing CMS analysis to identify the gene expression alterations that accurately reflect the biological features of SRCC.

Through this study, the clinicopathological severity of SRCC could be recognized. Microarray and subsequent integrative computational analyses were useful tools to comprehend the gene expression signature and to infer specific groups of genes hidden in the large information data.

\section{Acknowledgements}

The authors would like to thank Ms. Matsuo (Department of Surgery, Kurume University School of Medicine, Japan) and Ms. Kawaguchi (Research Center for Innovative Cancer Therapy, Kurume University School of Medicine, Japan) for performing the RNA extractions from the tissue samples and Ms. Otsu (Department of Surgery, Kurume University School of Medicine, Japan) for preparation of the slides for Hematoxylin and Eosin staining and immunohistochemistry staining.
Table VI. Gene set analysis of SRCC case 1, utilizing CMS caller.

\begin{tabular}{lrcrr}
\hline Gene set name & N Genes & Direction & P-values & FDR \\
\hline EMT & 199 & Up & 0.079 & 0.122 \\
TGF- $\beta$ & 60 & Up & 0.380 & 0.443 \\
LGR5 stem-cells & 62 & Down & 0.622 & 0.663 \\
CDX2 & 35 & Down & 0.124 & 0.173 \\
Fatty acids & 157 & Down & $<0.001^{\mathrm{a}}$ & $<0.001$ \\
Glycolysis & 200 & Down & $<0.001^{\mathrm{a}}$ & $<0.001$ \\
Differentiation & 612 & Down & $0.001^{\mathrm{a}}$ & 0.017 \\
Cell cycle & 200 & Down & 0.000 & 0.000 \\
WNT & 13 & Down & 0.245 & 0.312 \\
MYC & 58 & Down & $<0.001^{\mathrm{a}}$ & $<0.001$ \\
MSS & 80 & Down & 0.000 & 0.000 \\
HNF4 $\alpha$ & 58 & Down & $<0.001^{\mathrm{a}}$ & $<0.001$ \\
DNA repair & 148 & Down & $<0.001^{\mathrm{a}}$ & $<0.001$ \\
MSI & 29 & Down & 0.991 & 0.991 \\
\hline
\end{tabular}

N Genes, number of genes; FDR, false discovery ratio; EMT, epithelial-mesenchymal transition; TGF- $\beta$, transforming growth factor- $\beta$; LGR5, leucine-rich repeat containing $\mathrm{G}$ protein-coupled receptor 5; CDX2, caudal type homeobox 2; WNT, Wnt signaling pathway; MYC, Myc signaling pathway; MSS, microsatellite stable; HNF4 $\alpha$, hepatocyte nuclear factor $4 \alpha$; MSI, microsatellite instable. Up, upregulated; Down, downregulated. ${ }^{\mathrm{P}}<0.05$.

\section{Funding}

No funding was received.

\section{Availability of data and materials}

The datasets analyzed during the current study are available in the Array Express repository, on the web page https://www.ebi.ac.uk/arrayexpress/ ArrayExpress accession E-MTAB-9149.

\section{Authors' contributions}

KT conceived of the study and methodology, curated the data and wrote and drafted the original manuscript. TS conceived of the study, curated the data, analyzed the data and wrote, 
A

Cancer specific survival

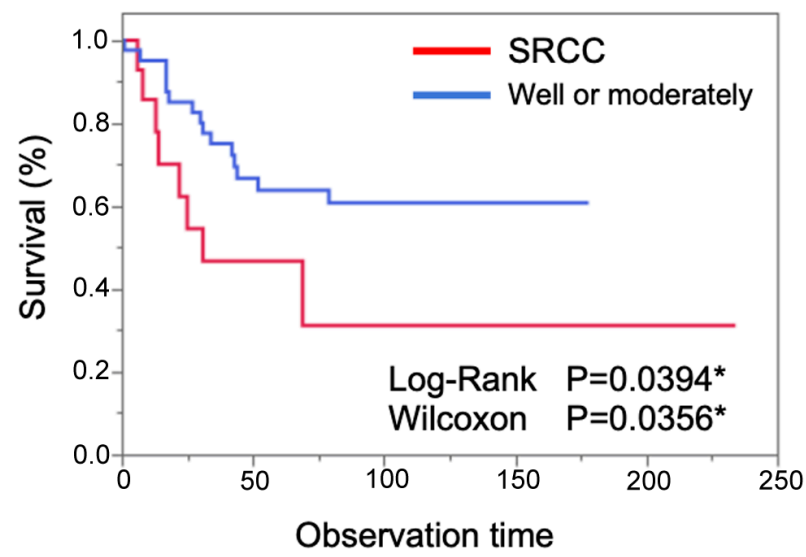

B Progression-free survival

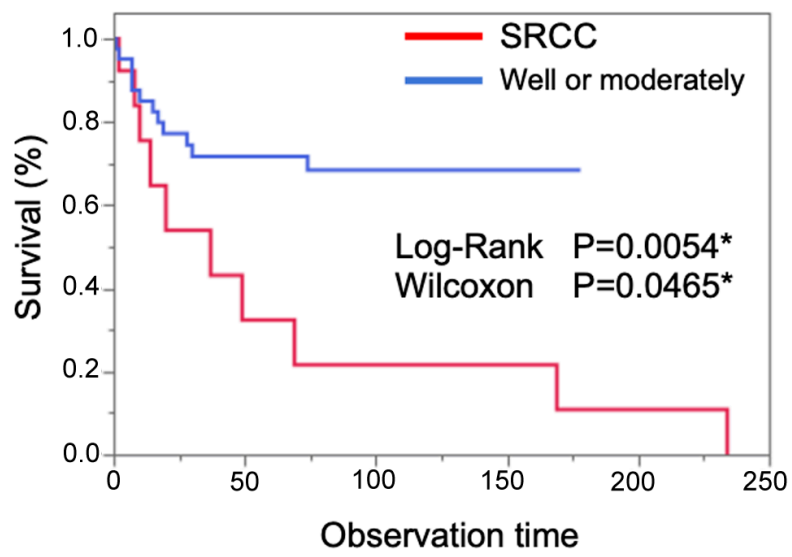

Figure 2. Survival comparisons between the case-control cohort of well or moderately differentiated adenocarcinoma cases and SRCC cases. (A) Cancer-specific survival. (B) Progression-free survival. Both survival curves were compared using the log-rank test. SRCC, signet ring cell carcinoma. ${ }^{\mathrm{P}}<0.05$.

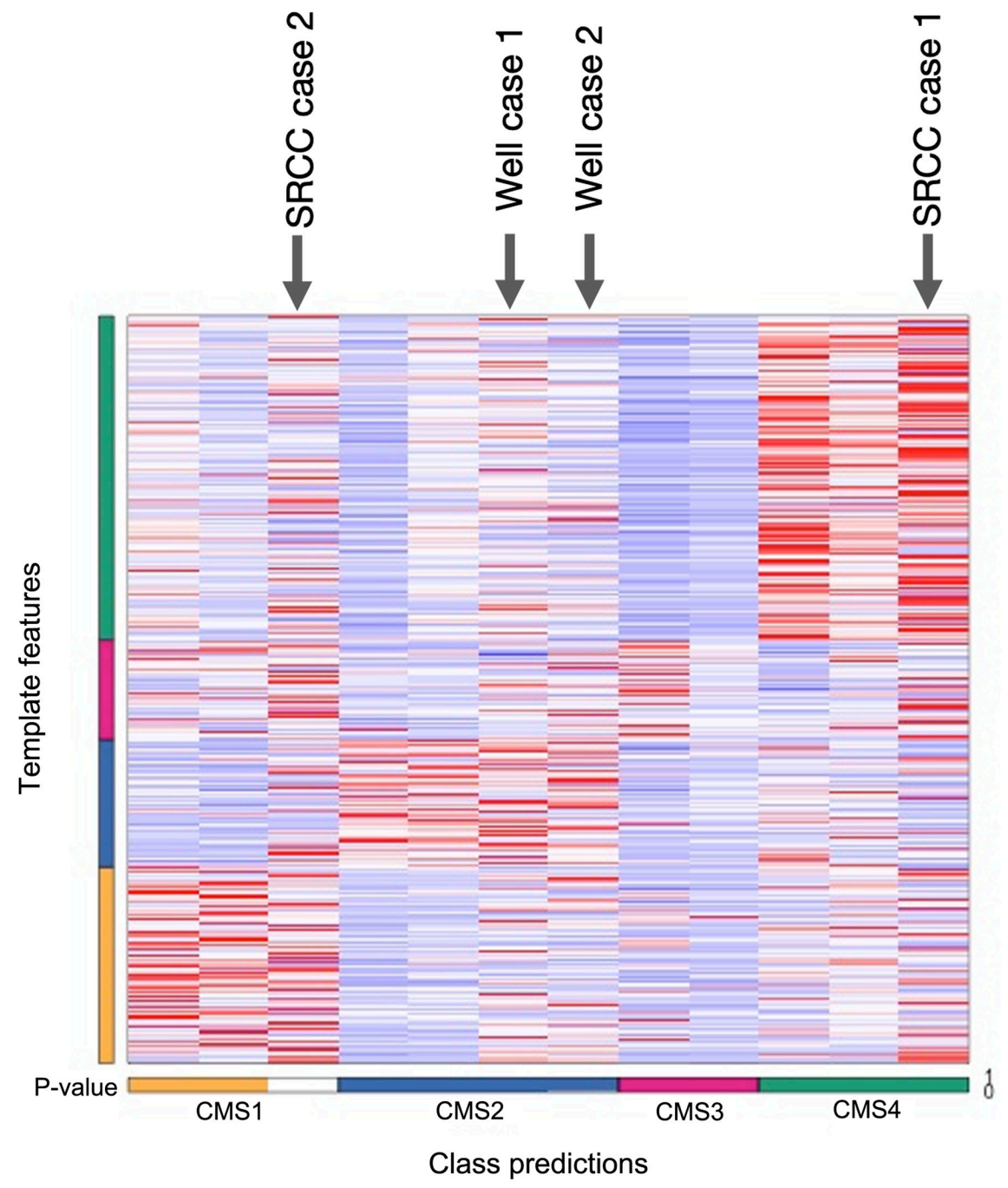

Figure 3. The color plot figure of twelve cases in CMS analysis in R utilizing the CMS caller package. The arrows are assigned SRCC and Well-differentiated adenocarcinoma samples. The remaining 9 samples data (contained in the CMS caller) were simultaneously used. Colour bars, each gene; red bar, high expression; blue bar, low expression. CMS, consensus molecular subtyping; SRCC, signet ring cell carcinoma.

reviewed and edited the manuscript. KI ran the software, was involved in data validation, performed formal analysis and visualized the data. AK performed the IHC experiment. SN, SS, KY, MK, TY, KF, KK, TO, TY and TM were involved 
in data curation. FF and JA reviewed, edited and drafted the manuscript, suggested important key points and interpreted the data in the current study. YA conceptualized the study, supervised the study and was involved in project administration. All authors read and approved the final manuscript.

\section{Ethics approval and consent to participate}

The current study was conducted in accordance with the provision of the Declaration of Helsinki and was approved by the Institutional Review Board of Kurume University Hospital (approval no. 245).

\section{Patient consent for publication}

The current study acquired written informed consent for publication from all of the patients enrolled in this study.

\section{Competing interests}

The authors declare that they have no competing interests.

\section{References}

1. Arifi S, Elmesbahi O and Amarti Riffi A: Primary signet ring cell carcinoma of the colon and rectum. Bull Cancer 102: $880-888,2015$.

2. Fu J, Wu L, Jiang M, Tan Y, Li D, Chen F, Jiang T and Du J: Signet ring cell carcinoma of resectable metastatic colorectal cancer has rare surgical value. J Surg Oncol 114: 1004-1008, 2016.

3. Cabibi D, Calascibetta A, Aragona F, Martorana A, Campione M and Sanguedolce R: Differing expression of metalloprotease and of adhesion molecules in signet-ring cell and intestinal colorectal carcinoma. Anticancer Res 29: 4417-4422, 2009.

4. Bellan A, Cappellesso R, Lo Mele M, Peraro L, Balsamo L, Lanza C, Fassan M and Rugge M: Early signet ring cell carcinoma arising from colonic adenoma: The molecular profiling supports the adenoma-carcinoma sequence. Hum Pathol 50: 183-186, 2016.

5. Wistuba II, Behrens C, Albores-Saavedra J, Delgado R, Lopez F and Gazdar AF: Distinct K-ras mutation pattern characterizes signet ring cell colorectal carcinoma. Clin Cancer Res 9: 3615-3619, 2003

6. Korphaisarn K, Morris V, Davis JS, Overman MJ, Fogelman DR, Kee BK, Dasari A, Raghav KPS, Shureiqi I, Trupti M, et al: Signet ring cell colorectal cancer: Genomic insights into a rare subpopulation of colorectal adenocarcinoma. Br J Cancer 121 505-510, 2019.

7. Liang Z, Yan D, Li G and Cheng H: Clinical analysis of primary colorectal signet-ring cell carcinoma. Clin Colorectal Cancer 17: e39-e 44, 2018.

8. Nitsche U, Friess H, Agha A, Angele M, Eckel R, Heitland W, Jauch KW, Krenz D, Nüssler NC, Rau HG, et al: Prognosis of mucinous and signet-ring cell colorectal cancer in a population-based cohort. J Cancer Res Clin Oncol 142: 2357-2366, 2016.

9. Börger ME, Gosens MJ, Jeuken JW, van Kempen LC, van de Velde CJ, van Krieken JH and Nagtegaal ID: Signet ring cell differentiation in mucinous colorectal carcinoma. J Pathol 212: 278-286, 2007.

10. Chen JS, Hsieh PS, Chiang JM, Yeh CY, Tsai WS, Tang R, Changchien CR and Wu RC: Clinical outcome of signet ring cell carcinoma and mucinous adenocarcinoma of the colon. Chang Gung Med J 33: 51-57, 2010.

11. Hyngstrom JR, Hu CY, Xing Y, You YN, Feig BW, Skibber JM, Rodriguez-Bigas MA, Cormier JN and Chang GJ: Clinicopathology and outcomes for mucinous and signet ring colorectal adenocarcinoma: Analysis from the national cancer data base. Ann Surg Oncol 19: 2814-2821, 2012.

12. Song IH, Hong SM, Yu E, Yoon YS, Park IJ, Lim SB, Kim JC, $\mathrm{Yu}$ CS and Kim J: Signet ring cell component predicts aggressive behaviour in colorectal mucinous adenocarcinoma. Pathology 51: 384-391, 2019.
13. Fukata K, Yuasa N, Takeuchi E, Miyake H, Nagai H, Yoshioka Y and Miyata K: Clinical and prognostic differences between surgically resected right-sided and left-sided colorectal cancer. Surg Today 50: 267-274, 2020.

14. Anthony T, George R, Rodriguez-Bigas M and Petrelli NJ: Primary signet-ring cell carcinoma of the colon and rectum. Ann Surg Oncol 3: 344-348, 1996.

15. Bae JM, Kim MJ, Kim JH, Koh JM, Cho NY, Kim TY and Kang GH: Differential clinicopathological features in microsatellite instability-positive colorectal cancers depending on CIMP status. Virchows Arch 459: 55-63, 2011.

16. Alvi MA, Loughrey MB, Dunne P, McQuaid S, Turkington R, Fuchs MA, McGready C, Bingham V, Pang B, Moore W, et al: Molecular profiling of signet ring cell colorectal cancer provides a strong rationale for genomic targeted and immune checkpoint inhibitor therapies. Br J Cancer 117: 203-209, 2017.

17. Tajiri K, Sudou T, Fujita F, Hisaka T, Kinugasa T and Akagi Y: Clinicopathological and corresponding genetic features of colorectal signet ring cell carcinoma. Anticancer Res 37: 3817-3823, 2017.

18. Yalcin S and Onguru O: BRAF mutation in colorectal carcinomas with signet ring cell component. Cancer Biol Med 14: 287-292, 2017.

19. Guinney J, Dienstmann R, Wang X, de Reyniès A, Schlicker A, Soneson C, Marisa L, Roepman P, Nyamundanda G, Angelino P, et al: The consensus molecular subtypes of colorectal cancer. Nat Med 21: 1350-1356, 2015.

20. Lenz HJ, Ou FS, Venook AP, Hochster HS, Niedzwiecki D, Goldberg RM, Mayer RJ, Bertagnolli MM, Blanke CD, Zemla $\mathrm{T}$, et al: Impact of consensus molecular subtype on survival in patients with metastatic colorectal cancer: Results from CALGB/SWOG 80405 (Alliance). J Clin Oncol 37: 1876-1885, 2019.

21. Stintzing S, Wirapati P, Lenz HJ, Neureiter D, Fischer von Weikersthal L, Decker T, Kiani A, Kaiser F, Al-Batran S, Heintges T, et al: Consensus molecular subgroups (CMS) of colorectal cancer (CRC) and first-line efficacy of FOLFIRI plus cetuximab or bevacizumab in the FIRE3 (AIO KRK-0306) trial. Ann Oncol 30: 1796-1803, 2019.

22. Mooi JK, Wirapati P, Asher R, Lee CK, Savas P, Price TJ, Townsend A, Hardingham J, Buchanan D, Williams D, et al: The prognostic impact of consensus molecular subtypes (CMS) and its predictive effects for bevacizumab benefit in metastatic colorectal cancer: Molecular analysis of the AGITG MAX clinical trial. Ann Oncol 29: 2240-2246, 2018.

23. Eide PW, Bruun J, Lothe RA and Sveen A: CMScaller: An R package for consensus molecular subtyping of colorectal cancer pre-clinical models. Sci Rep 7: 16618, 2017.

24. Almagro UA: Primary signet-ring carcinoma of the colon. Cancer 52: 1453-1457, 1983.

25. Secco GB, Fardelli R, Campora E, Lapertosa G, Gentile R, Zoli S and Prior C: Primary mucinous adenocarcinomas and signet-ring cell carcinomas of colon and rectum. Oncology 51: 30-34, 1994.

26. Belli S, Aytac HO, Karagulle E, Yabanoglu H, Kayaselcuk F and Yildirim S: Outcomes of surgical treatment of primary signet ring cell carcinoma of the colon and rectum: 22 cases reviewed with literature. Int Surg 99: 691-698, 2014.

27. Nitsche U, Zimmermann A, Spath C, Müller T, Maak M, Schuster T, Slotta-Huspenina J, Käser SA, Michalski CW, Janssen KP, et al: Mucinous and signet-ring cell colorectal cancers differ from classical adenocarcinomas in tumor biology and prognosis. Ann Surg 258: 775-783, 2013.

28. Hugen N, Verhoeven RH,Lemmens VE, van AartCJ, Elferink MA, Radema SA, Nagtegaal ID and de Wilt JH: Colorectal signet-ring cell carcinoma: Benefit from adjuvant chemotherapy but a poor prognostic factor. Int J Cancer 136: 333-339, 2015.

29. Kim D, Kim SY, Lee JS, Hong YS, Kim JE, Kim KP, Kim J, Jang SJ, Yoon YK and Kim TW: Primary tumor location predicts poor clinical outcome with cetuximab in RAS wild-type metastatic colorectal cancer. BMC Gastroenterol 17: 121, 2017.

30. Tung YS, Wu SC and Chen CP: Primary signet ring cell carcinoma of colorectum: An age- and sex-matched controlled study. Am J Gastroenterol 91: 2195-2199, 1996.

31. He J, Shin H, Wei X, Kadegowda AK, Chen R and Xie SK: NPC1L1 knockout protects against colitis-associated tumorigenesis in mice. BMC Cancer 15: 189, 2015.

32. Hu X, Matsumoto K, Jung RS, Weston TA, Heizer PJ, He C, Sandoval NP, Allan CM, Tu Y, Vinters HV, et al: GPIHBP1 expression in gliomas promotes utilization of lipoprotein-derived nutrients. Elife 8: e47178, 2019. 
33. Yang DA, Fan F, Camp ER, van Buren G, Liu W, Somcio R, Gray MJ, Cheng H, Hoff PM and Ellis LM: Chronic oxaliplatin resistance induces epithelial-to-mesenchymal transition in colorectal cancer cell lines. Clin Cancer Res 12: 4147-4153, 2006.

34. Hwang WL, Yang MH, Tsai ML, Lan HY, Su SH, Chang SC, Teng HW, Yang SH, Lan YT, Chiou SH and Wang HW: SNAIL regulates interleukin-8 expression, stem cell-like activity, and tumorigenicity of human colorectal carcinoma cells. Gastroenterology 141: 279-291,291.e1-e5, 2011.

35. Gasiulè S, Dreize N, Kaupinis A, Ražanskas R, Čiupas L, Stankevičius V, Kapustina Z̆, Laurinavičius A, Valius M and Vilkaitis G: Molecular insights into miRNA-driven resistance to 5-fluorouracil and oxaliplatin chemotherapy: miR-23b modulates the epithelial-mesenchymal transition of colorectal cancer cells. J Clin Med Res 8: 2115, 2019.

36. Bhangu A, Wood G, Mirnezami A, Darzi A, Tekkis P and Goldin R: Epithelial mesenchymal transition in colorectal cancer: Seminal role in promoting disease progression and resistance to neoadjuvant therapy. Surg Oncol 21: 316-323, 2012.

37. Sun L, Ke J, He Z, Chen Z, Huang Q, Ai W, Wang G, Wei Y, Zou X, Zhang S, et al: HES1 promotes colorectal cancer cell resistance To 5-Fu by inducing Of EMT and ABC transporter proteins. J Cancer 8: 2802-2808, 2017.
38. Fujikawa H, Tanaka K, Toiyama Y, Saigusa S, Inoue Y, Uchida K and Kusunoki M: High TrkB expression levels are associated with poor prognosis and EMT induction in colorectal cancer cells. J Gastroenterol 47: 775-784, 2012.

39. Ogino S, Brahmandam M, Cantor M, Namgyal C, Kawasaki T, Kirkner G, Meyerhardt JA, Loda M and Fuchs CS: Distinct molecular features of colorectal carcinoma with signet ring cell component and colorectal carcinoma with mucinous component. Mod Pathol 19: 59-68, 2006.

40. Kakar S, Deng G, Smyrk CT, Cun L, Sahai V and Kim SY: Loss of heterozygosity, aberrant methylation, BRAF mutation and KRAS mutation in colorectal signet ring cell carcinoma. Mod Pathol 25: 1040-1047, 2012.

This work is licensed under a Creative Commons Attribution-NonCommercial-NoDerivatives 4.0 International (CC BY-NC-ND 4.0) License. 